\title{
Soluble epoxide hydrolase inhibitor enhances synaptic neurotransmission and plasticity in mouse prefrontal cortex
}

\author{
Han-Fang Wu' ${ }^{1}$, Hsin-Ju Yen ${ }^{1}$, Chi-Chen Huang ${ }^{2,3}$, Yi-Chao Lee ${ }^{2,3}$, Su-Zhen Wu' ${ }^{4}$, Tzong-Shyuan Lee ${ }^{1,5}$
} and Hui-Ching Lin ${ }^{1,2,5^{*}}$

\begin{abstract}
Background: The soluble epoxide hydrolase (sEH) is an important enzyme chiefly involved in the metabolism of fatty acid signaling molecules termed epoxyeicosatrienoic acids (EETs). sEH inhibition (sEHI) has proven to be protective against experimental cerebral ischemia, and it is emerging as a therapeutic target for prevention and treatment of ischemic stroke. However, the role of sEH on synaptic function in the central nervous system is still largely unknown. This study aimed to test whether sEH C-terminal epoxide hydrolase inhibitor, 12-(3-adamantan-1-yl-ureido) dodecanoic acid (AUDA) affects basal synaptic transmission and synaptic plasticity in the prefrontal cortex area (PFC). Whole cell and extracellular recording examined the miniature excitatory postsynaptic currents (mEPSCs) and field excitatory postsynaptic potentials (fEPSPs); Western Blotting determined the protein levels of glutamate receptors and ERK phosphorylation in acute medial PFC slices.
\end{abstract}

Results: Application of the sEH C-terminal epoxide hydrolase inhibitor, AUDA significantly increased the amplitude of mEPSCs and fEPSPs in prefrontal cortex neurons, while additionally enhancing long term potentiation (LTP). Western Blotting demonstrated that AUDA treatment increased the expression of the N-methyl-D-aspartate receptor (NMDA) subunits NR1, NR2A, NR2B; the a-Amino-3-hydroxy-5-methyl-4-isoxazolepropionic acid (AMPA) receptor subunits GluR1, GluR2, and ERK phosphorylation.

Conclusions: Inhibition of sEH induced an enhancement of PFC neuronal synaptic neurotransmission. This enhancement of synaptic neurotransmission is associated with an enhanced postsynaptic glutamatergic receptor and postsynaptic glutamatergic receptor mediated synaptic LTP. LTP is enhanced via ERK phosphorylation resulting from the delivery of glutamate receptors into the PFC by post-synapse by treatment with AUDA. These findings provide a possible link between synaptic function and memory processes.

Keywords: Soluble epoxide hydrolase, Prefrontal cortex, Excitatory synaptic neurotransmission

\section{Background}

A ubiquitous bifunctional vertebrate enzyme, soluble epoxide hydrolase $(\mathrm{sEH})$, is comprised of a C-terminal epoxide hydrolase $(\mathrm{EH})$ domain and an N-terminal lipid phosphatase (PT) domain, and is widely distributed in a variety of mammalian organs and tissues such as liver, vascular endothelium, kidney [1-5]. Soluble epoxide

\footnotetext{
* Correspondence: hclin7@ym.edu.tw

'Institute and Department of Physiology, School of Medicine, National Yang-Ming University, Taipei 11221, Taiwan

${ }^{2}$ Ph.D. Program for Neural Regenerative Medicine, College of Medical Science and Technology, Taipei Medical University, Taipei 11031, Taiwan

Full list of author information is available at the end of the article
}

hydrolase $(\mathrm{sEH})$ is the major key regulator involved in the epoxyeicosatrienoic acids (EETs) metabolism effects [6]. Inhibition of $\mathrm{sEH}$ metabolism through pharmacological inhibition, or genetic deletion, has been shown to effectively increase endogenous EET levels. Due to this activity, sEH inhibitors are being developed as antihypertensive agents to prevent cardiac hypertrophy, inflammation and hyperglycemia in diabetic mice [7-10]. Thus sEH inhibition (sEHI) can have a somewhat similar effect to EET augmentation.

In the brain, sEH distributed in the cortex, striatum, hypothalamus and brain stem regions [11, 12]. The sEH 
is expressed in neural tissue and cerebral arterioles [2, 11, 13]. Immunohistochemistry technique observed that $\mathrm{sEH}$ is colocalized with neuron in cerebral cortex and striatum in the stroke brain [4]. Several animal studies, sEH activity and sEHEET pathway has been implicated in the disease associated neurotransmission imbalance such as anxiety-related behavior and seizure disorder [14-16]. Electrophysiology studies demonstrated that the C-terminal epoxide hydrolase (EH) inhibitor 12-(3-adamantan-1-yl-ureido) dodecanoic acid (AUDA) is similarly elevated the endogenous EETs to increase neuronal activity in the hypothalamus and brain stem of SHR rats [12]. The 5,6-EET increases the spontaneous excitatory postsynaptic current (sEPSC) frequency in spinal cord slices to affect the pain sensitivity [17]. Together, these studies raise the possibility that the EETs could modulate the physiological actions through the enhancement of excitatory neurotransmitter and neuronal activity. However, how the sEH-EET affect the basal levels of glutamate within prefrontal cortex remain unclear.

Glutamate, which is recognized as the major excitatory neurotransmission in the CNS [18], is involved in basal neurotransmission, synaptic plasticity, learning, and memory [19-21]. Activity dependent long term potentiation increases synaptic strength and requires a contribution from postsynaptic receptors such as $\alpha$-Amino-3-hydroxy-5-methyl-4-isoxazolepropionic acid (AMPA) receptors and Nmethyl-D-aspartate receptor (NMDA) receptors [22, 23]. NMDA receptor activation induces $\mathrm{Ca}^{2+}$ influx and triggers $\mathrm{Ca}^{2+} /$ calmodulin-dependent protein kinase II (CaMKII) thereby enhancing synaptic strength [24, 25]. Mitogen-activated protein kinase (MAPK) and phophatidylinositol-3kinase (PI3K) are both implicated in long term potentiation (LTP) and cognitive learning [26-28]. The AMPA receptor trafficking delivery mechanism to synaptic membranes plays an important role in LTP $[29,30]$. However, the effect and mechanisms by which sEH inhibitor, AUDA modulates synaptic plasticity remain unclear.

In current study, we aimed to test whether AUDA affects basal synaptic transmission and synaptic plasticity. Firstly, we determined the effects of AUDA on glutamatergic neurotransmission and synaptic efficacy in prefrontal cortex. Secondly, we further determined the expression of glutamate receptors and mechanisms underlying the AUDA-induced alteration in neurophysiology function. Finally, we wished to explore the possible signal pathway underlying AUDA-mediated enhancement of PFC glutamatergic neurotransmission. Here we found that the AUDA induces the enhancement of synaptic transmission, LTP and glutamate receptors in the prefrontal cortex. The sEH inhibition may increase the levels of EETs with subsequent activation of extracellular-signal-regulated kinases (ERKs) and modulation synaptic plasticity in the PFC area.

\section{Methods}

\section{Animals}

All procedures have been approved by the Institutional Animal Care and Use Committee of the College of Medicine, National Yang-Ming University (Taipei, Taiwan). Eight weeks old C57BL/6 mice were used in this study and housed four to a cage in a temperature-controlled $\left(24{ }^{\circ} \mathrm{C}\right)$ animal colony under a 12:12 light/dark cycle, with lights on at 7:00 AM. Pelleted chow and water were available ad libitum. All experimental procedures took place during the light cycle.

\section{Brain slice preparation and electrophysiological recordings of the prefrontal cortex}

Brain slices (400 $\mu \mathrm{m}$ thickness) were prepared as described previously [31]. Whole-cell recordings were made from the soma of visually-identified pyramidal-like neurons located in the PFC. Neurons were identified as projection neurons based on their intrinsic electrophysiological properties [32] in potassium gluconate-containing electrodes. The miniature excitatory postsynaptic currents (mEPSCs) were recorded in the presence of bicuculline (10 $\mu \mathrm{M}$; Tocris) Tetrodotoxin TTX (1 $\mu \mathrm{M}$; Tocris). We also examined paired pulse facilitation (PPF) in slices. The ratio of the amplitude of the first EPSP (fEPSP1) divided by the amplitude of the second EPSP (fEPSP2) was examined at $30 \mathrm{~ms}, 60 \mathrm{~ms}, 90 \mathrm{~ms}$ and 120-ms inter-pulse intervals. NMDA receptor dependent long term potentiation was induced by high frequency stimulation (HFS) protocols, 3 times of $1 \mathrm{~s}, 100 \mathrm{~Hz}$ stimulus trains separated by a 1 min interval between trains [33].

\section{Drugs}

AUDA, ( \pm ) 14 (15)- epoxy-5Z, 8Z, 11Z-eicosatrienoic acid (14,15-EET) and 14,15-epoxyeicosa-5 (Z)-enoic acid (14,15-EEZE) were obtained from Cayman. The stock solution was prepared in dimethyl sulphoxide (DMSO). The perused concentration of DMSO did not exceed $0.1 \%$ and had no effect on basal synaptic transmission. In the present study, the vehicle control was $0.1 \%$ DMSO in ACSF.

\section{Western blotting assay}

Brain tissues were dissected and lysed in a lysis buffer containing $1 \%$ Triton X-100, $0.1 \%$ SDS, 50 mM Tris$\mathrm{HCl}, \mathrm{pH}$ 7.5, $0.3 \mathrm{M}$ sucrose, 5 mM EDTA, 2 mM sodium pyrophosphate, $1 \mathrm{mM}$ sodium orthovanadate, $1 \mathrm{mM}$ enylmethylsulfonyl fluoride, supplemented with a complete protease inhibitor cocktail. Following sonication, lysates were centrifuged at $12,000 \mathrm{rpm}$ for $30 \mathrm{~min}$ to obtain supernatants. The protein concentration of supernatants was measured using a Bradford assay and equal amount of protein were separated by SDS-PAGE electrophoresis, 
transferred to Immobilon-P membranes (Millipore). and incubated in $5 \%$ nonfat dry milk for $60 \mathrm{~min}$. Western blot analysis used GluR1 (1: 1000; Abcam, Cambridge, UK), GluR2 $^{-}$(1: 1000; Abcam, Cambridge, UK) and $\beta$ - Actin (1:1000; Millipore, Billerica, MA, USA), NR1 (1: 1000; Abcam, Cambridge, UK), NR2A (1: 1000; Millipore, Billerica, MA, USA) ,NR2B (1: 2000; Millipore, Billerica, MA, USA), D2 receptor (1: 1000; Millipore, Billerica, MA, USA,), ERK (1: 2000; Cell signaling Technology, Boston, MA, USA), p-GluR1 (1: 1000; Abcam, Cambridge, UK), pNR2B (1: 1000; Cell signaling Technology, Boston, MA, USA) antibody, reacted overnight at $4{ }^{\circ} \mathrm{C}$, and then incubated with HRP-conjugated secondary antibodies for $1 \mathrm{~h}$ at room temperature. Immunoreactivity was detected by ECL Plus detection reagent (PerkinElmer, Boston, MA, USA). Films were exposed at different times to ensure the optimum density but not saturated and followed by densitometry. Protein levels were first normalized to internal control levels for each sample and then were measured as fold changes with respect to controls.

\section{Reverse transcription (RT) and quantitative (q) real-time polymerase chain reaction (PCR)}

Total RNA was isolated using the TRIzol RNA extraction kit (Invitrogen), and $0.5 \mu \mathrm{g}$ of RNA was subject to reverse transcription-PCR with M-MLV (Invitrogen). The specific PCR oligonucleotides for these NMDA and AMPA subunits, and $\beta$-actin as internal control listed as followed:

\section{NR1-F:5'CTCATCTCTAGCCAGGTCTA-3' NR1-R: 5'-TCGCATCATCTCAAACCAGAC-3' NR2A-F: 5'-ACTCCACACTGCCCATGAAC-3' NR2A-R: 5'-TTGTTCCCCAAGAGTTTGCTT-3' NR2B-F: 5'-GTTTGATGAAATCGAGCTGGC-3' NR2B-R: 5'-TCCAGTTCCTGCAGGGAGTT-3' GluR1-F: 5'-AGGTTTGCTTTGTCACAA-3' GluR1-R: 5'CTTCTCCAGGTC CTGAAA -3' GluR2-F: 5'-ATCAAGAAGCCTCAGAAGTCCAAA -3' GluR2-R: 5'-CTGACCCCAATGTAGGCAAAC-3' $\beta$-actin-F: 5'-TACAACCTCCTTGCAGCTCC-3' $\beta$-actin-R: 5'-ACAATGCCGTGTTCAATGG-3'}

The PCR products were separated by $1 \%$ agarosegel electrophoresis and visualized with ethidium bromide staining. Quantitative RT-PCR was carried out using the StepOnePlus ${ }^{\mathrm{Tm}}$ Real-Time PCR Systems and KAPA SYBR FAST qPCR Master Mix according to the manufacturer's instructions. In brief, $\beta$-actin was used as the internal control for quantitation of the expression of target genes in samples from vehicle control vs. AUDA-treated brain tissue.

\section{Statistical analysis}

All values are expressed as the mean \pm SEM. Electrophysiology responses and the protein level of vehicle control and AUDA-exposed group, were assessed using the Student's $t$-test. The stimulus-response (input-output) relationships, PPF and LTP analyzed by One-way ANOVA or Two-way ANOVA was followed with Bonferroni's post hoc test. The difference between treated groups was considered significant if $p<0.05$.

\section{Results}

Effects of sEH inhibitor AUDA on prefrontal cortex neurons We assessed effect of sEHI on both basic neuronal features and excitatory synaptic transmission in the PFC. We utilized the protocol that othodromic stimuli applied to the layer II of rat prefrontal cortex slices elicited excitatory postsynaptic currents (EPSCs) in layer V. Superfusion of AUDA for $10 \mathrm{~min}$ resulted in significantly increased EPSC amplitudes (Fig. 1a). This result indicated that sEHI enhanced excitatory synaptic transmission in the PFC. To examine whether the intrinsic excitability of PFC neurons is changed by treatment of the sEH inhibitior AUDA, whole-cell patch clamp recordings were performed on PFC slices. The pyramidal neurons in layer $\mathrm{V}$ neurons have an average resting membrane potential of $-61 \pm$ $1.6 \mathrm{mV}$ and an input resistance of $107 \pm 7.8 \mathrm{M} \Omega$ in the vehicle control, and an average resting membrane potential $-60 \pm 2.3 \mathrm{mV}$ with an input resistance of $111 \pm 5.2 \mathrm{M} \Omega$ after AUDA treatment $(n=5)$. As shown in Fig. 1b, there is no difference between the vehicle control state and AUDA treatment in the number of action potentials that could be elicited in response to 150-pA depolarizing current pulses. Thus, AUDA treatment cannot significantly alter either the resting membrane potential or the input resistance. Application of different concentrations of AUDA, i.e. 1, 5,10 $\mu \mathrm{M}$ enhanced the initial response of fEPSPs by $138.9 \pm 5.8 \%(n=5), 184.8 \pm$ $10.2 \%(n=5)$ and $190 \pm 5.8 \%(n=5)$ of baseline respectively (Fig. 1c). Thus perfusion with $1,5,10 \mu \mathrm{M}$ of AUDA significantly enhanced the fEPSPs compared to vehicle control $(\mathrm{F}(3,16)=36.3 \mathrm{P}<0.001)$.

\section{Effects of epoxyeicosatrienoic acids (EETs) on prefrontal cortex neurons}

The enhancement of fEPSPs by sEH inhibitor could be due to its presence and to further promote the levels of EETs. Thus we determined whether the 14,15-EET produce similar postsynaptic glutamatergic neurotransmission effect of AUDA. We found that fEPSPs was significantly increased during 14,15EET-treated (134.2 $\pm 12.1 \%, n=5)$ of baseline at 

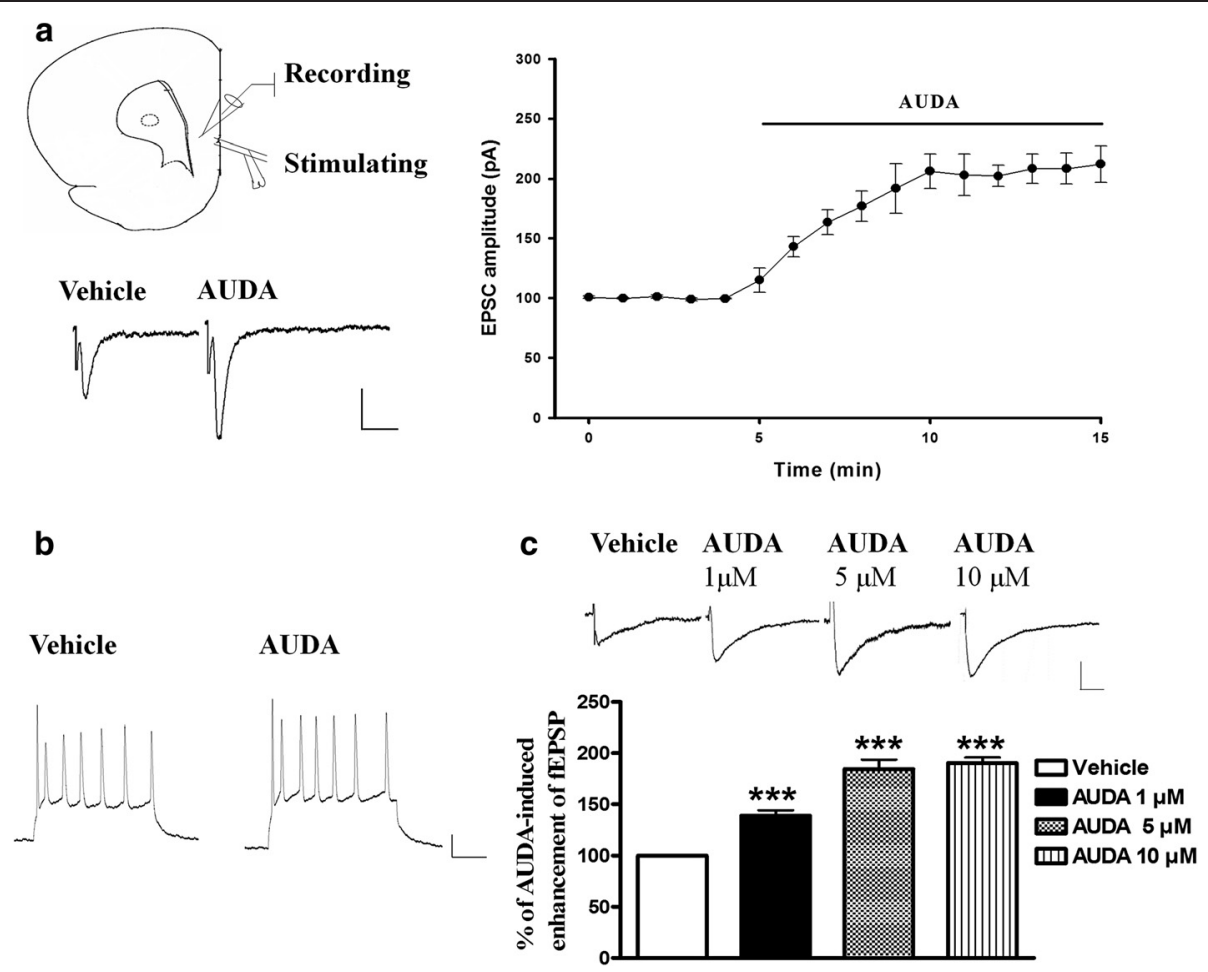

Fig. 1 The sEH inhibitor, AUDA, alters synaptic response in PFC pyramidal neurons. a Schematic illustration of prefrontal cortex slices and placement of electrodes. The stimulating electrode was placed on layer II and the recording electrode was placed on layer V. Evoked EPSC was recorded of AMPA EPSC which was isolated in the presence of NMDA antagonist (APV $50 \mu \mathrm{M}$ ) and GABA receptor (bicuculline $10 \mu \mathrm{M}$ ) antagonists. (scale $40 \mathrm{~ms}$, 50 pA). Time course showed that treatment of $10 \mu \mathrm{M}$ AUDA increased the EPSC amplitude. $\mathbf{b}$ Traces showed that the number of spikes evoked by a current pulse during control/ACSF and perfusion with $10 \mu \mathrm{M}$ AUDA (scale $100 \mathrm{~ms}, 20 \mathrm{pA}$ ). c The percentage of fEPSP response with $1 \mu \mathrm{M}, 5 \mu \mathrm{M}$ or $10 \mu \mathrm{M}$ AUDA treatment. ${ }^{* *} p<0.001$ vs. vehicle control

PFC synapse (Fig. 2a). We further examined whether selective EET antagonist could inhibit the enhancement of fEPSPs by AUDA. The selective EET antagonist 14, 15-EEZE $(1 \mu \mathrm{M})(n=5)$ combination with AUDA $(5 \mu \mathrm{M})(n=5)$ were added into the PFC slice. As Shown in Fig. 2b, enhancement of fEPSPs by AUDA was dramatically inhibited by combining with $14,15$-EEZE at $1 \mu \mathrm{M} 104.2 \pm 3.1 \%, n=5)$. Thus AUDA induces enhancement of fEPSPs via increasing levels of EETs.

\section{AUDA enhances the I-O efficiency and glutamatergic transmission at PFC synapses}

To determine whether the enhancement of fEPSPs was due to the alteration of the glutamate neurotransmitter mediated basal synapse response, we tested the relationship between the strength of a stimulus and its effect on response (input-output, IO) for fEPSPs in PFC neurons. The data showed that higher doses of AUDA induced larger fEPSPs responses which are determined at $2 \times$ threshold than vehicle control state (Fig. 3a). Different stimulation intensities were applied to observe the amplitude of the fEPSPs (Fig. 3b; two-way ANOVA, effect of treatment $F_{(3,96)}=23.37, p<0.001$; effect of stimulus intensity $F_{(4,96)}=244.2, p<0.001$; interaction $F_{(12,96)}=$ 14.07, $p<0.001$ ), and these results showed that AUDA enhanced the basal synaptic neurotransmission.

To determine whether AUDA treatment alters the presynaptic efficiency of excitatory synaptic transmission, we tested the PPF in PFC slices. The ratio of the fEPSP amplitude of the second fEPSP to the amplitude of the first fEPSP was examined at 30, 60, 90, 120 and 150 interpulse intervals (Fig. 3c). There was no difference in presynaptic glutamate release probability with AUDA treatment in PFC neurons (Fig. 3d, two-way ANOVA, effect of treatment $F_{(3,76)}=0.19$, $p=0.92$; effect of stimulus intensity $F_{(4,76)}=34.2, p<0.001$; interaction $\left.F_{(12,76)}=0.21, p=0.99\right)$. Hence the effect of AUDA in PFC did not result in the alteration of presynaptic probability of neurotransmitter release.

We further investigated the alteration of basal excitatory synaptic transmission in PFC neurons by AUDA treatment. PFC slices were made and wholecell recordings were made from the soma of visually identified pyramidal-like neurons located in the PFC. Figure $4 \mathrm{a}, \mathrm{b}$ shows that AUDA $(10 \mu \mathrm{M})$ treatment resulted in a significantly higher mEPSCs amplitude compared to vehicle state $(p<0.05)$. The mean 
a<smiles>ICCCCCCCI</smiles>
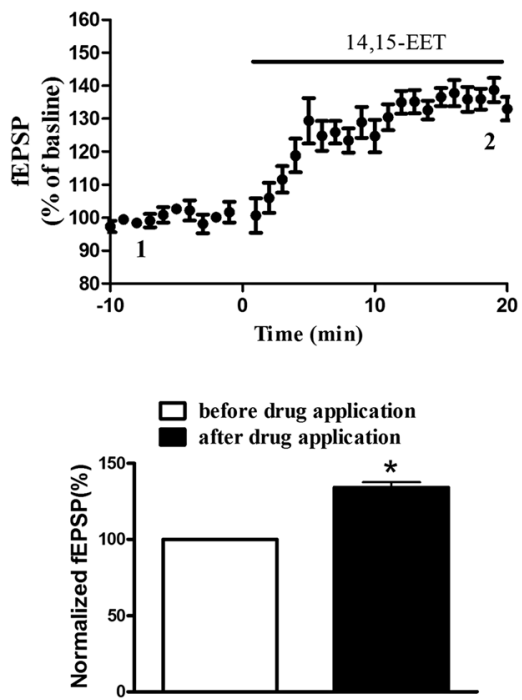

b
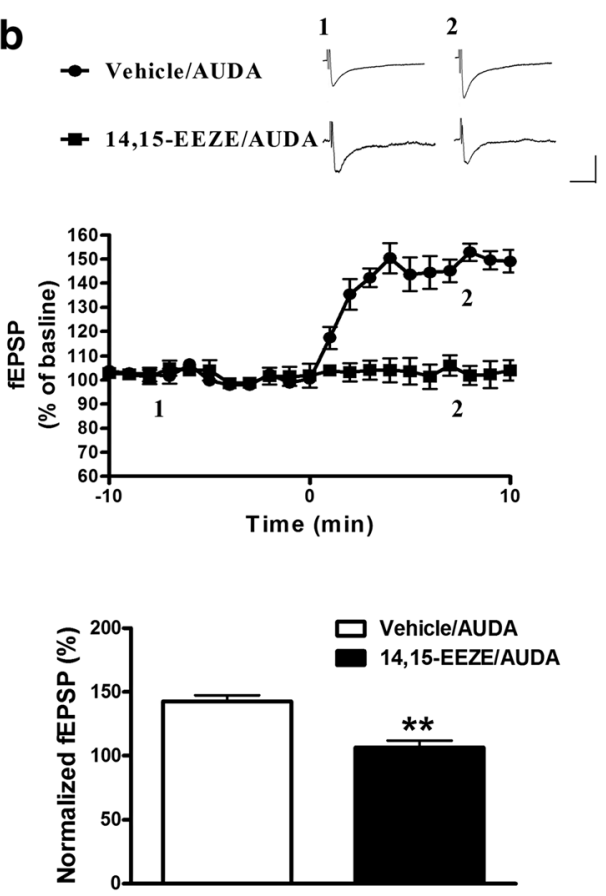

Fig. 2 Enhancement of synaptic response by EETs at prefrontal cortex synapse. a PFC slice was perfused with 14,15-EET (10 $\mu M, n=5)$, and the percentage of fEPSPs response was measured. $\mathbf{b}$ The percentage of fEPSPs response was measured in the presence of vehicle combination with AUDA or $14,15-\mathrm{EEZE}$ in combination with AUDA. ${ }^{*} p<0.05 \mathrm{vs}$. control, ${ }^{* *} p<0.01 \mathrm{vs}$. vehicle/AUDA group

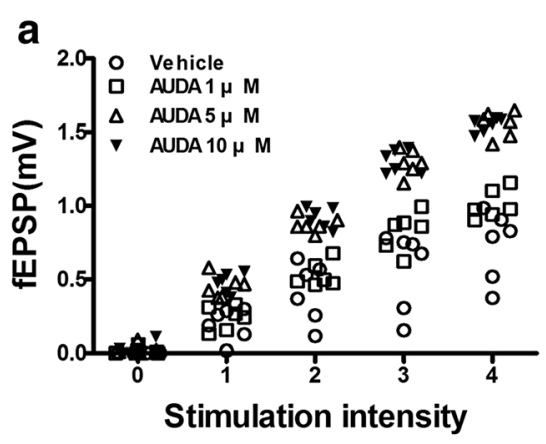

C $30 \mathrm{~ms}$

Vehicle

AUDA

$1 \mu \mathrm{M}$

AUDA 5

$\mu \mathrm{M}$

AUDA

$10 \mu \mathrm{M}$

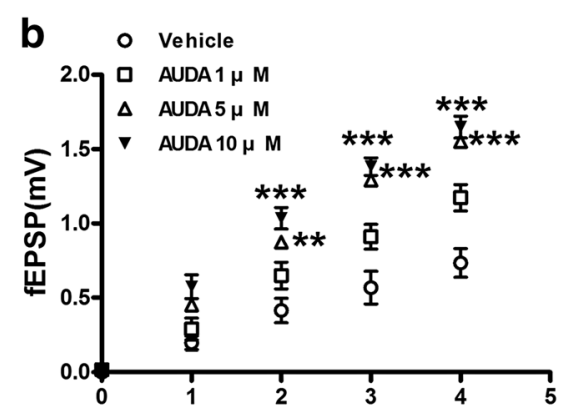

d

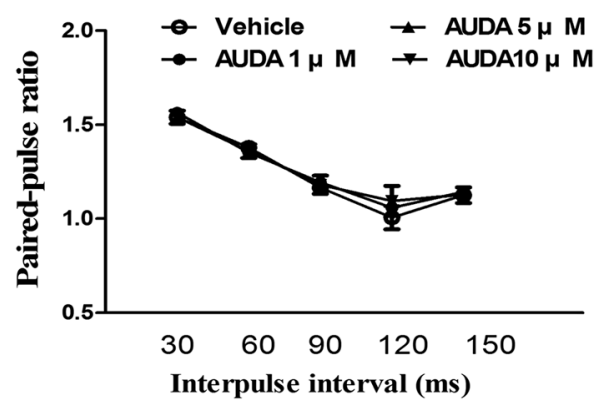

Fig. 3 The sEH inhibitor, AUDA, increases postsynaptic efficiency of I-O glutamatergic transmission but not presynaptic glutamate release in PFC slice. a The I-O relationship was measured by the stimulation intensity and amplitude of fEPSP in the different concentration of $1 \mu \mathrm{M}, 5 \mu \mathrm{M}$ or $10 \mu \mathrm{M}$ AUDA. b Mean value of I-O curves of glutamatergic transmission in PFC slices. c Sample traces were an average of 5-10 successive responses. The paired-pulse fEPSPs were evoked with intervals of $30 \mathrm{~ms}$ and $90 \mathrm{~ms}$. Calibration; 50 pA, $30 \mathrm{~ms}$. d Paired-pulse ratio was evoked at $30 \mathrm{~ms}, 60 \mathrm{~ms}, 90 \mathrm{~ms}, 120 \mathrm{~ms}, 150 \mathrm{~ms}$ intervals in the different concentration of AUDA. ${ }^{* *} p<0.01,{ }^{* * *} p<0.001 \mathrm{vs}$. vehicle control 

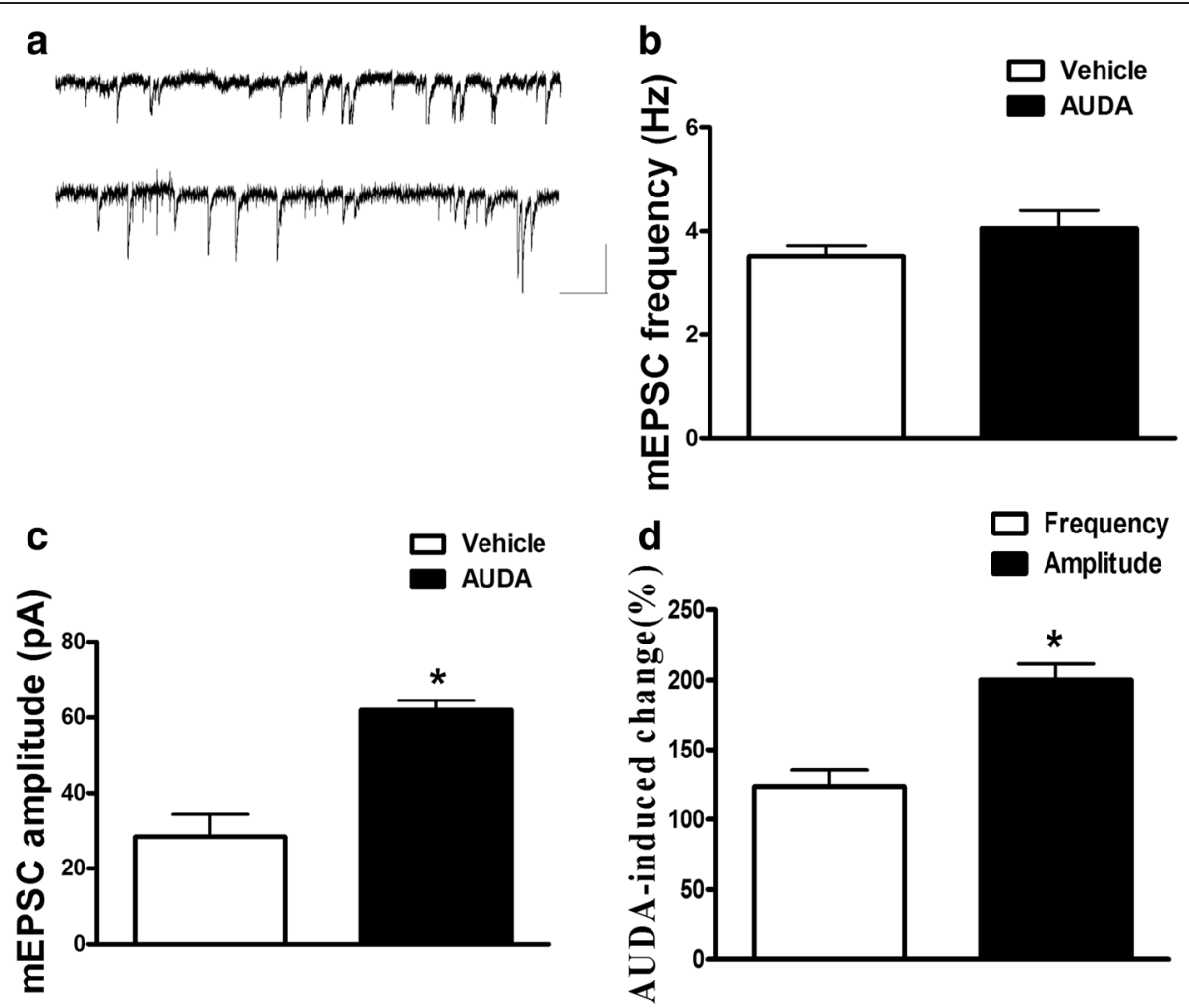

Fig. 4 Enhancement of miniature excitatory postsynaptic current (mEPSC) amplitude in the PFC neurons by AUDA treatment. a Sample traces of mEPSCs were taken from brainslices of vehicle control, AUDA treatment in PFC neurons. mEPSCs were recorded in the PFC neurons at a holding potential of $-70 \mathrm{mV}$ in the presence of TTX $(1 \mu \mathrm{M})$. Calibration: 50 pA, $100 \mathrm{~ms}$. (b and $\mathbf{c}$ ) The summary frequency and amplitude were measured for vehicle control and AUDA groups. (d) The AUDA-induced changes were measured in percentage of frequency-/amplitude- of mEPSCs response at $10 \mu \mathrm{M}$ of $\mathrm{AUDA}^{*} p<0.05$ vs. vehicle control

amplitude of the mEPSCs in the vehicle and AUDA treated groups was $28.4 \pm 5.9 \mathrm{pA}$ and $62.0 \pm 2.6 \mathrm{pA}(p$ $<0.05$ ) respectively (Fig. 4c, d). The mean frequencies of $\mathrm{mEPSCs}$ in the vehicle and AUDA treated groups were $3.5 \pm 0.3 \mathrm{~Hz}$ and $4,1 \pm 0.4 \mathrm{~Hz}$ (Fig. $4 \mathrm{~b}$ ). These results demonstrated that enhancement of mEPSCs amplitude was observed in AUDA treated PFC slices, and the frequency of mEPSCs was not affected.

\section{AUDA enhances the long term potentiation (LTP) in the PFC neurons}

We investigated if $\mathrm{sEH}$ inhibition was required for, or involved in, long term potentiation. We confirmed that applied high frequency stimulation (3 times for $1 \mathrm{sec}$ at $100 \mathrm{~Hz}$ stimuli separated by interval of $1 \mathrm{~min}$; HFS) induced long term potentiation in PFC neurons. As shown in Fig. 5a, we used HFS protocol successfully induced LTP. The degree of HFS-induced LTP was enhanced in the presence of AUDA (Fig. 5b). We further compared the amplitude of synapse at 10 or 60 min following tetanus HFS treatment in the absence or presence of AUDA. The results showed a higher response for fEPSPs at $10 \mathrm{~min}$ after HFS (vehicle: $126.3 \pm 4.8 \%$ of baseline, $n=10$ from 5 rats. AUDA: $180.3 \pm 3.5 \%$ of baseline, $n=10$ from 6 rats.) which maintained LTP at $60 \mathrm{~min}$ after HFS (vehicle: $145.2 \pm 7.4 \%$ of baseline, $n=10$ from 5 rats. AUDA: $172.1 \pm 6.3 \%$ of baseline, $n=10$ from 6 rats) in the presence of AUDA (Fig. 5c, d). The results suggest that AUDA can modulate synaptic efficiency to facilitate the formation of and subsequently maintain LTP $(p<0.01)$.

The expression of glutamate receptors is increased by the inhibition of $\mathrm{sEH}$

PFC glutamatergic neurotransmission is increased by inhibiting $\mathrm{sEH}$. This may be caused by the alteration of glutamate receptor expression and function [34-37]. We determined whether the expression of AMPA receptors and NMDA receptors were altered by AUDA. Rats were decapitated and PFC slices were prepared. Slices were incubated with AUDA $(10 \mu \mathrm{M})$ for $10 \mathrm{~min}$ and washed to remove the drug. The protein levels of the NMDA receptor were: NR1 (121.1 $\pm 6.6 \%$ of vehicle, $n=5)$, NR2A (158.3 $\pm 13.7 \%$ of vehicle, $n=5)$ and NR2B $(135.2 \pm 9.3 \%$ of vehicle, $n=5)$. The levels of 

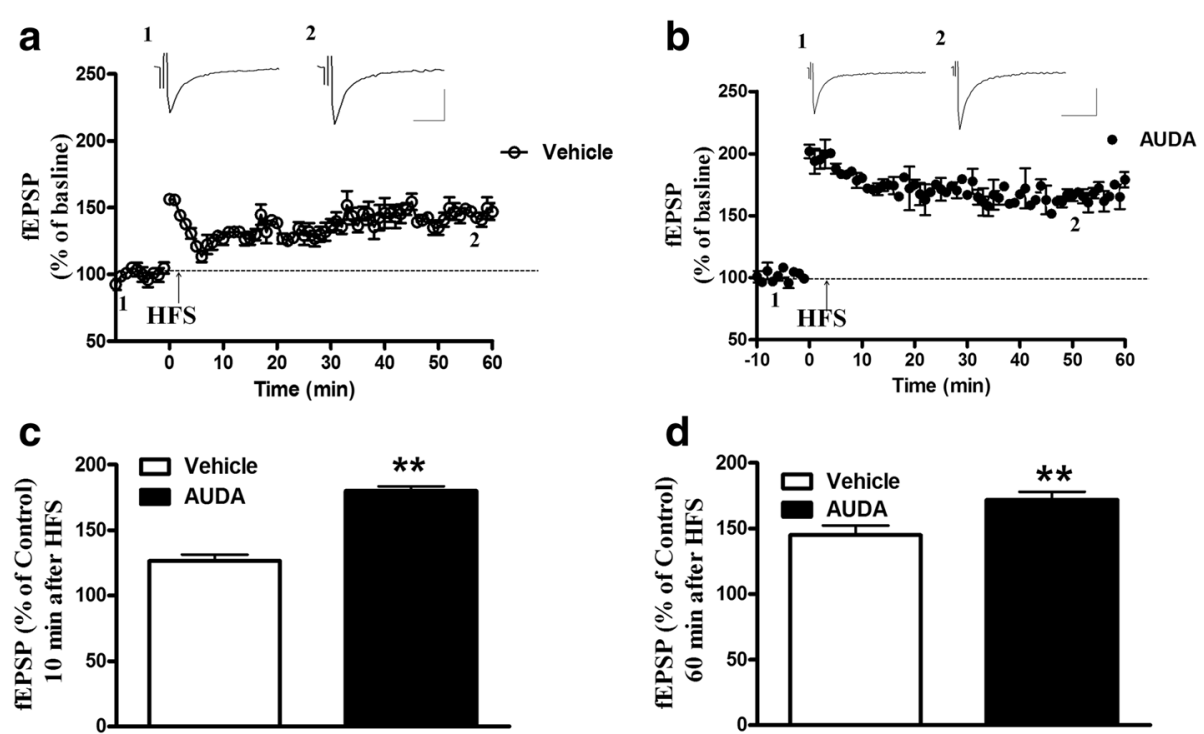

Fig. 5 SEH inhibitor, AUDA, facilitates LTP in PFC slice. a The graph represents the mean \pm SEM slope of fEPSPs plotted against time. Applied with $3 \times$ high-frequency stimulation of $100 \mathrm{~Hz}$ for $1 \mathrm{~s}$ induced LTP. $\mathbf{b}$ In the presence of $1 \mu \mathrm{M}$ AUDA, the enhancement of LTP was observed. $\mathbf{c}$ Comparison of fEPSPs slope potentiation 10 min after tetanus in the absence or presence AUDA is shown. $\mathbf{d}$ Comparison of fEPSPs slope potentiation 60 min after tetanus in the absence or presence AUDA is shown. ${ }^{* *} p<0.01$ vs. vehicle control

AMPA receptor GluR1 subunit (167.3 $\pm 10.4 \%$ of control, $n=5)$ and GluR2 subunit $(129.9 \pm 10.9 \%$ of vehicle, $n=5)$ were significantly higher in the AUDA-exposed than in the Vehicle control state $(p<0.05$ or $p<0.01)$. The dopamine D2 receptor has been reported to be able to contribute to the enhanced synaptic efficacy of the hippocampus by co-treating with cocaine and high frequency stimulation [38]. We also found that AUDA treatment significantly increased the protein level of the dopamine D2 receptor $(n=5)$ (Fig. 6a, b) $(p<0.05)$.
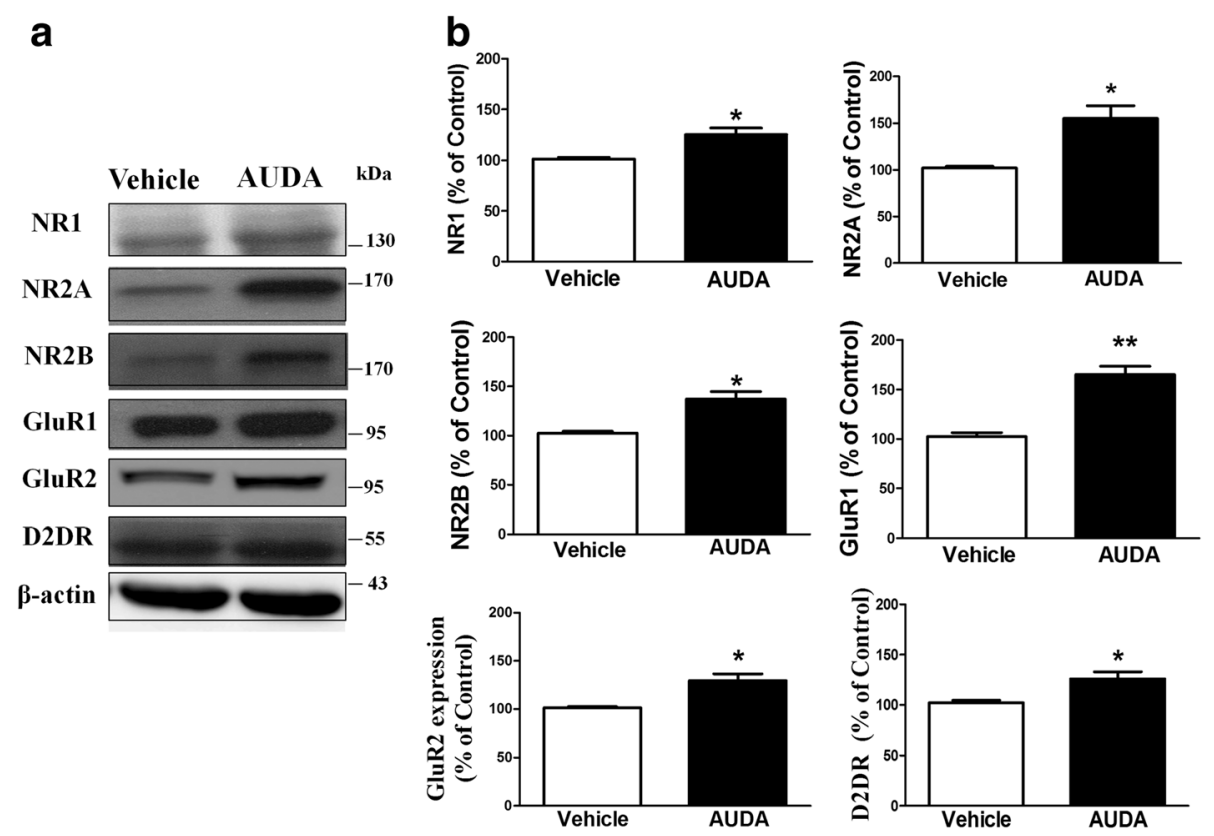

Fig. 6 Synaptic receptors expression in PFC slices could be increased by the SEH inhibitor, AUDA. a The PFC slices were incubated with AUDA $(10 \mu \mathrm{M})$ for $10 \mathrm{~min}$ and then washed to remove AUDA. One hour later, homogenate from the PFC was prepared and blotted with antibodies AMPA receptors subunit GluR1, GluR2, NMDA receptor subunits NR1, NR2A, NR2B and dopamine receptor D2 in the PFC slices. $\mathbf{b}$ The bar graph showed the normalized band intensity of synaptic receptors in PFC slice. ${ }^{*} p<0.05,{ }^{* *} p<0.01$ vs. vehicle control 
One possibility for the increase in NR1, NR2A, NR2B, GluR1, GluR2 levels is the increment in total protein expression. We therefore performed RT-PCR and real time qPCR to measure NR1, NR2A, NR2B, GluR1, GluR2 mRNA in tissue homogenates from PFC. By using RTPCR, the mRNA levels of NR1, NR2A, NR2B, GluR1, GluR2 were: NR1 $(95.3 \pm 6.6 \%$ of vehicle, $n=3)$, NR2A $(97.1 \pm 1.4 \%$ of vehicle, $n=3)$ and NR2B $(105.2 \pm 7.4 \%$ of vehicle, $n=3)$. The levels of GluR1 $(98.3 \pm 7.9 \%$ of vehicle, $n=3)$ and GluR2 (110.3 $\pm 4.9 \%$ of vehicle, $n=3$ ) (Fig. 7a, b). Real-Time qPCR measured NR1 $(96.6 \pm 3.5 \%$ of vehicle, $n=3)$, NR2A $(112.8 \pm 16.5 \%$ of vehicle, $n=3)$ and NR2B $(93.2 \pm 12.9 \%$ of vehicle, $n=3)$. The levels of GluR1 $(104.6 \pm 4.9 \%$ of vehicle, $n$ $=3)$ and GluR2 $(98.3 \pm 16.9 \%$ of vehicle, $n=3)$ (Fig. $7 \mathrm{c}$ ). The mRNA levels of NR1, NR2A, NR2B, GluR1, GluR2 examination showed no changes after AUDA treatment compared to vehicle control group.

We further confirmed that the increased protein levels are due to post-translational modification. We examined the phosphorylation of NR2B, GluR1, GluR2 in the PFC region treatment with AUDA. In the presence of AUDA increased NR2B phosphorylation (139.9 \pm $9.9 \%$ of vehicle, $n=4)$, GluR1phosphorylation (184.2 $\pm 7.6 \%$ of vehicle, $n=4$ ) and GluR2 phosphorylation $(119.4 \pm 4.1 \%$ of vehicle, $n=4)$ (Fig.8).

We wished to explore the possible signal pathway underlying AUDA-mediated enhancement of PFC glutamatergic neurotransmission. Many studies have demonstrated that the EETs attenuated NF-K B activation and increased PI3K/Akt and p42/p44 MAPK signaling in endothelial cells and cardiomyocytes [39]. Thus $\mathrm{sEH}$ inhibition may increase the levels of EETs with subsequent activation of ERK44/42 and modulation synaptic plasticity in the PFC area. As shown in 9A, the phosphorylated levels of ERK44 (140.8 \pm $10.5 \%, n=5)$ and ERK42 (158.1 $\pm 14.7 \%, n=5)$ were significantly increased by AUDA treatment compared with vehicle control $(p<0.05)$ (Fig. 9a). The total ERKs did not change as a result of AUDA-treatment compared with vehicle control. These data indicated that AUDA could induce ERK44/42 activation in PFC region.

Our results demonstrated that the degree of HFSinduced LTP was enhanced in the presence of AUDA (Fig. 5b). We therefore tested whether AUDA combination with HFS could further induce ERK44/42 activation in PFC region. The phosphorylated degree of
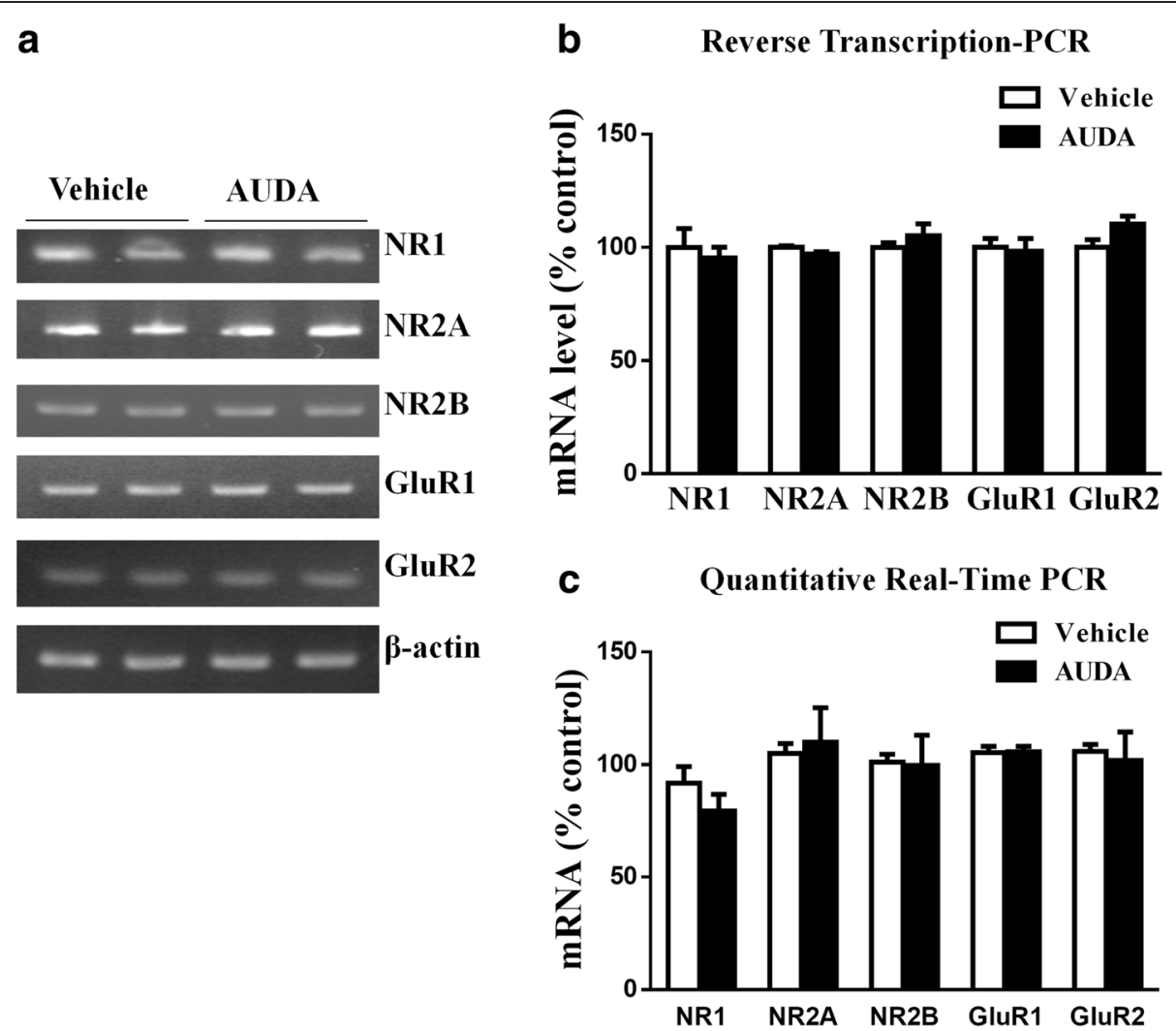

Fig. 7 The sEH inhibitor AUDA does not affect the total amount of NR1, NR2A, NR2B, GluR1, GluR2 mRNA levels. a, b Total RNA was isolated from the PFC slices by treating with AUDA and mRNA expression for NR1, NR2A, NR2B, GluR1, GluR2 were analyzed with RT-PCR and (c) Real-Time qPCR. The mRNA expression for $\beta$-actin was used as an internal control 

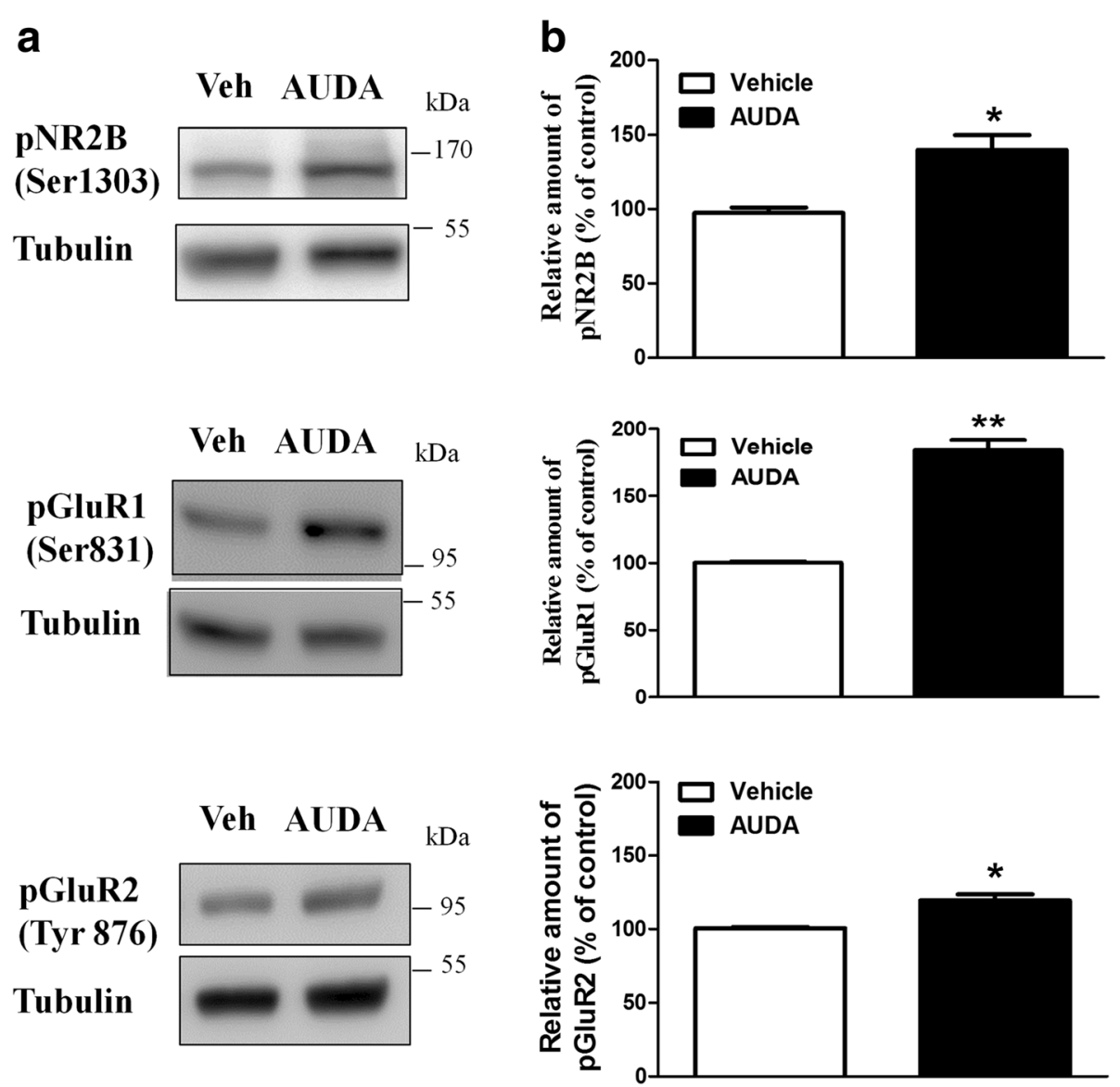

Fig. 8 The SEH inhibitor AUDA increases the phosphorylation of protein levels by AUDA. a The tissue lysate of PFC area was prepared and blotted with antibodies against the phosphorylated Ser1303 on NR2B, phosphorylated Ser831 on GluR1 and phosphorylated Tyr876 on GluR2. b The bar graph showed the normalized band intensity of phosphorylated synaptic receptors in PFC slice. ${ }^{*} p<0.05,{ }^{* *} p<0.01$ vs. vehicle control

ERK44/42 (ERK44: $123.1 \pm 4.7 \% n=5$; ERK42: $153.6 \pm$ $8.4 \%, n=5$ ) was increased with LTP. The phosphorylated levels of ERK44/42 were further increased in the presence of AUDA combination with HFS-induced LTP protocol (ERK44: $159.8 \pm 10.3 \% n=5$; ERK42: $179.6 \pm$ $7.5 \%, n=5$ ) (Fig. 9b). In addition, COX2 has been reported to be implicated in long-term potentiation [40]. Here we demonstrated that there was no difference in the level of COX-2 normalized with GAPDH between vehicle control state and AUDA-treated groups (106.4 \pm $13.2 \%$ of vehicle, $n=3$ ) (Fig. 9c) $(p>0.05)$.

\section{Discussion}

In the present study, we provided evidence that sEHI enhanced the amplitude of evoked EPSCs and mEPSCs responses in PFC synapses by using whole-cell patch clamp recordings. Extracellular recordings consistency revealed increased fEPSPs and increased input-output plots in a dose dependent manner after AUDA treatment at PFC synapse from brain slices. Plasticity PPF is a neurotransmitter efficacy index of presynapse released probability [41]. An observed unchanged PPF, coupled with increased fEPSPs suggests alteration of postsynaptic glutamate neurotransmission in sEHI treated neurons. Moreover, sEHI facilitated a HFS-induced LTP. Finally, the protein levels of GluR1, GluR2, NR2A and NR2B were increased after treatment with SEHI AUDA. The AUDA further increases the LTP-induced ERK phosphorylation. These results provide new insights into the role that $\mathrm{sEHI}$ may play in the regulation of synaptic efficacy in the PFC area.

A report has demonstrated $\mathrm{sEH}$ specific expression in pyramidal neuron of layer $\mathrm{V}$ in the dorsomedial cerebral cortex [13]. It is still unknown how sEH exerts its effects in modulating the basal synaptic responses. Here we demonstrated that the $\mathrm{SEH}$ inhibitor, AUDA, induced the enhancement of synaptic neurotransmission. Enhanced levels of EETs resulting from $\mathrm{sEH}$ inhibition have been reported [42, 43]. We applied the 14, 15-EET also increases the fEPSPs response. The enhancement of postsynaptic response induced by sEH inhibitor, AUDA is blocked by selective EET antagonist. Thus sEH inhibitor causes the 
a

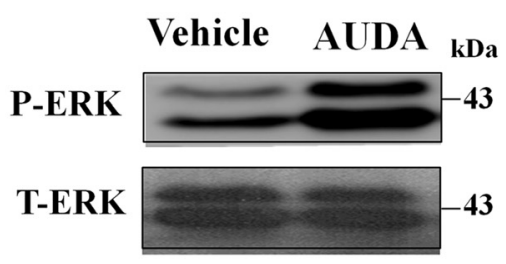

b

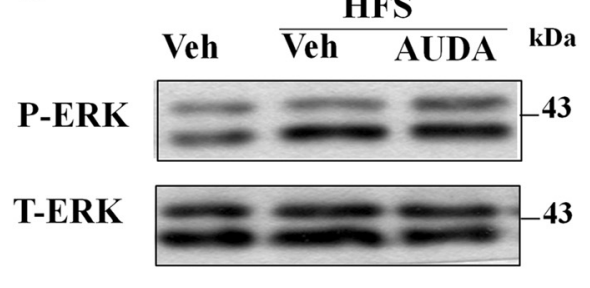

C

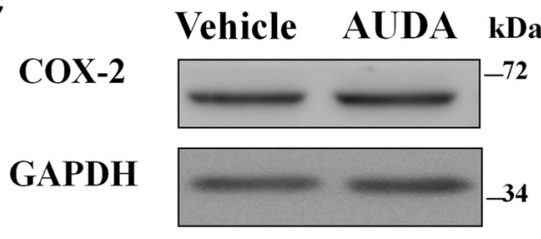

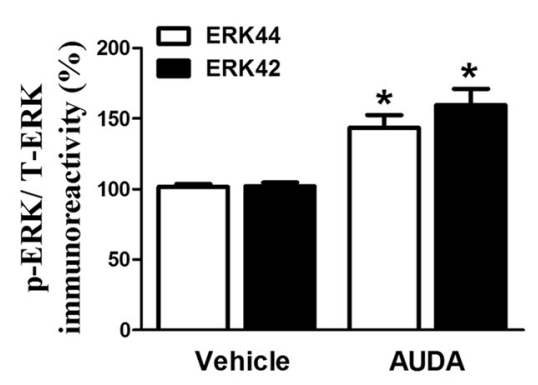
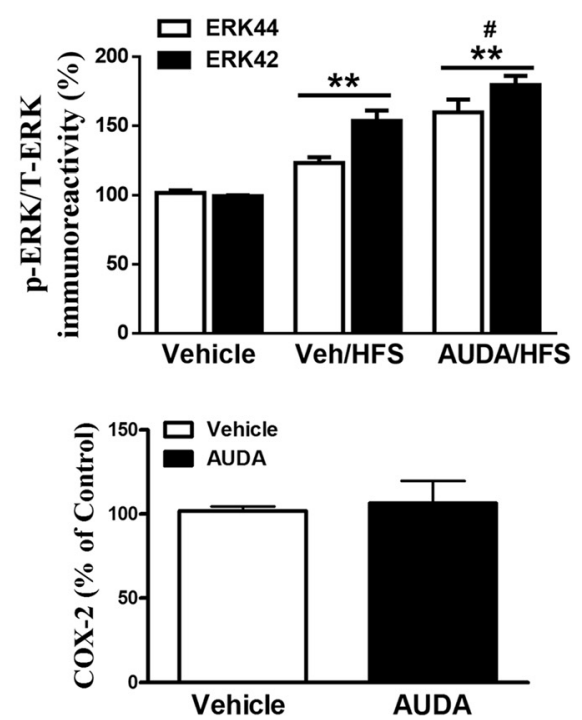

Fig. 9 The sEH inhibitor AUDA induced the phosphorylation of ERK in PFC slices. a The PFC slices were incubated with AUDA (10 $\mu M$ ) for 10 min and then washed to remove AUDA. One hour later, homogenate from the PFC was prepared and blotted with antibodies directly against the active form of ERKs. AUDA-induced increase of ERKs phosphorylation in the PFC slices is shown. AUDA treatment increased the phosphorylated levels of ERK42 and ERK44 relative to the vehicle controls (ACSF). No change was observed when the cellular extract was blotted with an antibody that recognizes total ERKs, suggesting that the observed pERKs increments were not due to an increase in the total amount of ERKs. $\mathbf{b}$ Here shows the phosphorylated levels of ERK42 and ERK44 among the vehicle control, vehicle/HFS and AUDA/HFS groups. c The homogenate from the PFC following AUDA treatment was prepared and blotted with antibodies directly against the COX-2. GAPDH was the internal control * $p<0.05$, ${ }^{* *} p<0.01$ vs. vehicle control; \#p $<0.05$ vs. vehicle HFS group

levels of EETs to increase and thereby enhances the synaptic excitatory response in the PFC region. Our results showed that the $\mathrm{SEH}$ inhibition enhanced the amplitude of evoked EPSCs and mEPSCs responses, but not PPF in PFC synapses. Moreover, sEH inhibition induced the increase of LTP magnitude in PFC synapses. These results suggest that $\mathrm{sEH}$ inhibition affects postsynaptic efficacy and is beneficial for maintaining LTP.

AMPA receptors and NMDA receptors have been considered as the major ionic glutamate receptors that are associated with excitatory neurotransmission and the mediated the LTP in the brain $[22,23,44]$. The synaptic response increment by $\mathrm{sEH}$ inhibition could be due to the increase of neurotransmitter release from presynaptic or increase in the number of glutamate postsynaptic receptors. Our electrophysiology data showed the PPF did not change by $\mathrm{sEH}$ inhibitor treatment, suggesting that $\mathrm{sEH}$ inhibitor did not alter the presynaptic neurotransmission at PFC synapse. Furthermore, we observed that inhibition of $\mathrm{sEH}$ at the PFC synapse enhances the protein levels of the NMDA receptor NR1 subunit, NR2A subunit and NR2B subunit; AMPA receptor GluR1 subunit, GluR2 subunit in the PFC region. Thus sEH inhibitor increases synaptic response mostly via altering the number of glutamate postsynaptic receptors. The altered protein levels of AMPA receptors and NMDA receptors by inhibiting of $\mathrm{sEH}$ did not enhance mRNA level of GluR1, GluR2, NR1 NR2A and NR2B in the PFC region. Our data further revealed that sEH inhibitor resulted in increased NR2B, GluR1 and GluR2 phosphorylation state, suggesting that posttranslational modification is involved in $\mathrm{sEH}$ inhibitor altered synaptic response. The enhancement of phosphorylated protein levels is required for surface glutamate receptors stability. The phosphorylated protein of glutamate 
receptors also involved in regulation of NMDA receptors and AMPA receptors function $[45,46]$. Further studies are needed to confirm how the phosphorylated protein in modulation of synaptic plasticity by sEH inhibition.

We investigated the molecular pathway under $\mathrm{sEH}$ inhibition treatment in PFC region. Previous studies demonstrated that sEH inhibition enhanced levels of EETs and increased PI3K/Akt and p42/p44 MAPK signaling in endothelial cells, cardiomyocytes and diabetic nephropathy disease $[39,42,43,47]$. Additionally, MAPKs pathway and phosphorylated level of ERKs are classically required for NMDA-dependent LTP and longterm memory [48-52]. Our data showed that the phosphorylated level of ERKs was significantly increased after LTP. We also found that the sEH inhibitor AUDA not only induced an increase in phosphorylated ERKs in the mPFC slices, but also augmented LTP response, which further increased the phosphorylated ERK; thus, enhanced LTP and potentiated activation of ERKs which delivers glutamate receptors into the PFC post-synapse by treatment with sEH inhibition. Dopamine D2 receptors have been reported to be involved in cocaine facilitated protein synthesis dependent LTP [38, 48]. Our results demonstrated a sEHI AUDA-induced increase in dopamine D2 receptor activation in the PFC. Thus, the effects of sEHI AUDA could also be due to activation of D2 receptors that facilitates the formation and continuation of LTP. In addition, cyclooxygenase 2 (COX-2) has been reported to be required for synaptic plasticity and acquisition of memory process $[40,51]$. We found that the protein level of COX-2, as detected by Western Blotting, showed no difference between $\mathrm{sEH}$ inhibition treatment and vehicle control in PFC slices. We know that the prefrontal cortex is important for emotional memory and experience memory [53-57]. Here we demonstrated that SEHI AUDA induced synaptic related molecular changes in NMDA receptor subunits NR1, NR2A and NR2B; and AMPA receptor subunits GluR1, GluR2; and in the dopamine D2 receptor. sEHI AUDA contributes to the degree of HFS-induced LTP in the PFC region. These findings could also suggest that synaptic properties of sEHI AUDA in PFC could lead to the modulation of learning and memory.

Additionally, animal studies have shown that acute or chronic pre-administration of sEH inhibitor could protect infarct size region and improve the neurodeficit score which damaged by cerebral ischemia $[4,58]$. The glutamate transmission is dramatically increased during ischemia [59]. Preconditioning by treated with glutamate prevented oxygen-glucose deprivation (OGD)-induced neuronal injury blocked by AMPA receptor antagonist and NMDA receptor antagonist in primary cultured cortical neurons [60]. Our finding demonstrated that AUDA-induced the enhancement of glutamatergic neurotransmission in PFC area and other studies have shown OGD increased massive glutamatergic neurotransmission. Thus the underlying mechanisms of the neuronal protective effect of AUDA on stroke or how AUDA mediates regulation of vascular function or excitatory transmission still need to be assessed. The role of AUDA may regulate different responses underlie basal condition and pathological condition. In the present study, we observed that AUDA enhanced glutamatergic transmission and LTP in PFC area may be beneficial to learning and memory.

In summary, we showed that sEH inhibition induced an enhancement of PFC neuronal synaptic neurotransmission. This enhancement of synaptic neurotransmission is associated with an enhanced postsynaptic glutamatergic receptor and postsynaptic glutamatergic receptor mediated synaptic response. By contrast, the paired-pulse ratio is not changed after inhibition of sEH activity. The presynaptic mechanism is not involved in sEH inhibitorinduction of synaptic response. Furthermore, enhanced LTP may be via ERK phosphorylation resulting from the delivery of glutamate receptors into the PFC by postsynapse by treatment with AUDA. Our study provides a foundation for understanding PFC related synaptic efficacy and PFC related cognitive functioning with respect to learning and memory.

\section{Conclusions}

We first report that $\mathrm{sEH}$ inhibitor mediated excitatory neurotransmission in the PFC area. Inhibition of sEH enhances LTP which through the ERK phosphorylation resulting from the delivery of glutamate receptors into the PFC area. It is suggested that inhibition of sEH may modulate the synaptic function and learning memory formation.

\section{Competing interests}

The authors declare that they have no competing interests.

\section{Authors' contributions}

HC Lin conceived and designed the experiments. HF Wu, HJ Yen, HC Lin, CC Huang, YC Lee performed the experiments. HF Wu, HC Lin, HJ Yen analyzed the data. SZ Wu, TS Lee, CC Huang, YC Lee contributed reagents/materials/ analysis tools. HF Wu and HC Lin wrote the paper. All authors read and approved the final manuscript.

\section{Acknowledgments}

We thank Ya-Ting Hsu for carefully read on the first draft of manuscript. This study was supported by grants MOST 103-2320-B-010 -014-MY2, MOST 102-2321-B-010 -025, MOST 103-2321-B-010-016 from the Ministry of Science and Technology of Taiwan. This study was also supported by Yen Tjing Ling Medical Fundation (Cl-104-13), Taiwan. CMFHR10466 from Chi-Mei Medical Center, Tainan, Taiwan. Brain Research Center, National Yang-Ming University and a grant from Ministry of Education, Aim for the Top University Plan, Taiwan. The funding institutions of this study had no further role in the study design, the collection, analysis, and interpretation of data, the writing of this paper, or the decision to submit it for publication. 


\section{Author details}

${ }^{1}$ Institute and Department of Physiology, School of Medicine, National Yang-Ming University, Taipei 11221, Taiwan. ${ }^{2}$ Ph.D. Program for Neural Regenerative Medicine, College of Medical Science and Technology, Taipei Medical University, Taipei 11031, Taiwan. ${ }^{3}$ Center for Neurotrauma and Neuroregeneration, Taipei Medical University, Taipei 11031, Taiwan. ${ }^{4}$ Department of Anesthesiology, Chi-Mei Medical Center, Tainan, Taiwan. ${ }^{5}$ Brain Research Center, National Yang-Ming University, Taipei 11221, Taiwan.

\section{Received: 7 June 2015 Accepted: 9 October 2015}

\section{Published online: 22 October 2015}

\section{References}

1. Johansson C, Stark A, Sandberg M, Ek B, Rask L, Meijer J. Tissue specific basal expression of soluble murine epoxide hydrolase and effects of clofibrate on the mRNA levels in extrahepatic tissues and liver. Arch Toxicol. 1995;70(1):61-3.

2. Koerner IP, Jacks R, DeBarber AE, Koop D, Mao P, Grant DF, et al. Polymorphisms in the human soluble epoxide hydrolase gene EPHX2 linked to neuronal survival after ischemic injury. J Neurosci. 2007;27(17):4642-9. doi:10.1523/JNEUROSCI.0056-07.2007.

3. Rawal S, Morisseau C, Hammock BD, Shivachar AC. Differential subcellular distribution and colocalization of the microsomal and soluble epoxide hydrolases in cultured neonatal rat brain cortical astrocytes. J Neurosci Res. 2009;87(1):218-27. doi:10.1002/jnr.21827.

4. Zhang W, Koerner IP, Noppens R, Grafe M, Tsai HJ, Morisseau C, et al. Soluble epoxide hydrolase: a novel therapeutic target in stroke. J Cerebral Blood Flow Metab. 2007;27(12):1931-40. doi:10.1038/sj.jcbfm.9600494.

5. Marowsky A, Burgener J, Falck JR, Fritschy JM, Arand M. Distribution of soluble and microsomal epoxide hydrolase in the mouse brain and its contribution to cerebral epoxyeicosatrienoic acid metabolism. Neuroscience. 2009;163(2):646-61. doi:10.1016/j.neuroscience.2009.06.033.

6. Fang X, Kaduce TL, Weintraub NL, Harmon S, Teesch LM, Morisseau C, et al. Pathways of epoxyeicosatrienoic acid metabolism in endothelial cells. Implications for the vascular effects of soluble epoxide hydrolase inhibition. J Biol Chem. 2001;276(18):14867-74. doi:10.1074/jbc.M011761200.

7. Inceoglu B, Jinks SL, Schmelzer KR, Waite T, Kim IH, Hammock BD. Inhibition of soluble epoxide hydrolase reduces LPS-induced thermal hyperalgesia and mechanical allodynia in a rat model of inflammatory pain. Life Sci. 2006;79(24):2311-9. doi:10.1016/j.lfs.2006.07.031.

8. Schmelzer KR, Inceoglu B, Kubala L, Kim IH, Jinks SL, Eiserich JP, et al. Enhancement of antinociception by coadministration of nonsteroidal anti-inflammatory drugs and soluble epoxide hydrolase inhibitors. Proc Natl Acad Sci U S A. 2006;103(37):13646-51. doi:10.1073/pnas.0605908103.

9. Zhao X, Yamamoto T, Newman JW, Kim IH, Watanabe T, Hammock BD, et al. Soluble epoxide hydrolase inhibition protects the kidney from hypertension-induced damage. J Am Soc Nephrol. 2004;15(5):1244-53.

10. Zhang W, Otsuka T, Sugo N, Ardeshiri A, Alhadid YK, lliff JJ, et al. Soluble epoxide hydrolase gene deletion is protective against experimental cerebral ischemia. Stroke. 2008;39(7):2073-8. doi:10.1161/STROKEAHA.107.508325.

11. Iliff J, Jia J, Nelson J, Goyagi T, Klaus J, Alkayed NJ. Epoxyeicosanoid signaling in CNS function and disease. Prostaglandins Other Lipid Mediat. 2010;91(3-4):68-84. doi:10.1016/j.prostaglandins.2009.06.004.

12. Sellers KW, Sun C, Diez-Freire C, Waki H, Morisseau C, Falck JR, et al. Novel mechanism of brain soluble epoxide hydrolase-mediated blood pressure regulation in the spontaneously hypertensive rat. FASEB J. 2005;19(6):626-8. doi:10.1096/fj.04-3128fje.

13. Bianco RA, Agassandian K, Cassell MD, Spector AA, Sigmund CD. Characterization of transgenic mice with neuron-specific expression of soluble epoxide hydrolase. Brain Res. 2009;1291:60-72. doi:10.1016/ j.brainres.2009.07.060.

14. Luria A, Morisseau C, Tsai HJ, Yang J, Inceoglu B, De Taeye B, et al. Alteration in plasma testosterone levels in male mice lacking soluble epoxide hydrolase. Am J Physiol Endocrinol Metab. 2009;297(2):E375-83. doi:10.1152/ajpendo.00131.2009.

15. Inceoglu B, Zolkowska D, Yoo HJ, Wagner KM, Yang J, Hackett E, et al. Epoxy fatty acids and inhibition of the soluble epoxide hydrolase selectively modulate GABA mediated neurotransmission to delay onset of seizures. PLoS One. 2013;8(12):e80922. doi:10.1371/journal.pone.0080922.

16. Hung YW, Hung SW, Wu YC, Wong LK, Lai MT, Shih YH, et al. Soluble epoxide hydrolase activity regulates inflammatory responses and seizure generation in two mouse models of temporal lobe epilepsy. Brain Behav Immun. 2014. doi:10.1016/j.bbi.2014.07.016.

17. Sisignano M, Park CK, Angioni C, Zhang DD, von Hehn C, Cobos EJ, et al 5,6-EET is released upon neuronal activity and induces mechanical pain hypersensitivity via TRPA1 on central afferent terminals. J Neurosci. 2012;32(18):6364-72. doi:10.1523/JNEUROSCI.5793-11.2012.

18. Niciu MJ, Kelmendi B, Sanacora G. Overview of glutamatergic neurotransmission in the nervous system. Pharmacol Biochem Behav. 2012;100(4):656-64. doi:10.1016/j.pbb.2011.08.008.

19. Whitlock JR, Heynen AJ, Shuler MG, Bear MF. Learning induces long-term potentiation in the hippocampus. Science. 2006;313(5790):1093-7. doi:10.1126/science.1128134.

20. Bailey CH, Giustetto M, Huang YY, Hawkins RD, Kandel ER. Is heterosynaptic modulation essential for stabilizing Hebbian plasticity and memory? Nat Rev Neurosci. 2000;1(1):11-20. doi:10.1038/35036191.

21. Sacktor TC. PKMzeta, LTP maintenance, and the dynamic molecular biology of memory storage. Prog Brain Res. 2008;169:27-40. doi:10.1016/S00796123(07)00002-7

22. Malenka RC. Synaptic plasticity and AMPA receptor trafficking. Ann N Y Acad Sci. 2003;1003:1-11.

23. Foster KA, McLaughlin N, Edbauer D, Phillips M, Bolton A, Constantine-Paton $M$, et al. Distinct roles of NR2A and NR2B cytoplasmic tails in longterm potentiation. J Neurosci. 2010;30(7):2676-85. doi:10.1523/ JNEUROSCI.4022-09.2010.

24. Otmakhov N, Tao-Cheng JH, Carpenter S, Asrican B, Dosemeci A, Reese TS, et al. Persistent accumulation of calcium/calmodulin-dependent protein kinase II in dendritic spines after induction of NMDA receptor-dependent chemical long-term potentiation. J Neurosci. 2004;24(42):9324-31. doi:10.1523/JNEUROSCI.2350-04.2004.

25. Zhang YP, Holbro N, Oertner TG. Optical induction of plasticity at single synapses reveals input-specific accumulation of alphaCaMKII. Proc Natl Acad Sci U S A. 2008;105(33):12039-44. doi:10.1073/pnas.0802940105.

26. Eales KL, Palygin O, O'Loughlin T, Rasooli-Nejad S, Gaestel M, Muller J, et al. The MK2/3 cascade regulates AMPAR trafficking and cognitive flexibility. Nat Commun. 2014:5:4701. doi:10.1038/ncomms5701.

27. Racaniello M, Cardinale A, Mollinari C, D'Antuono M, De Chiara G, Tancredi $V$, et al. Phosphorylation changes of CaMKII, ERK1/2, PKB/Akt kinases and CREB activation during early long-term potentiation at Schaffer collateralCA1 mouse hippocampal synapses. Neurochem Res. 2010;35(2):239-46. doi:10.1007/s11064-009-0047-0.

28. Raymond CR, Redman SJ, Crouch MF. The phosphoinositide 3-kinase and p70 S6 kinase regulate long-term potentiation in hippocampal neurons. Neuroscience. 2002:109(3):531-6.

29. Man HY, Wang Q, Lu WY, Ju W, Ahmadian G, Liu L, et al. Activation of PI3kinase is required for AMPA receptor insertion during LTP of mEPSCs in cultured hippocampal neurons. Neuron. 2003;38(4):611-24.

30. Mitsushima D, Ishihara K, Sano A, Kessels HW, Takahashi T. Contextual learning requires synaptic AMPA receptor delivery in the hippocampus. Proc Natl Acad Sci U S A. 2011;108(30):12503-8. doi:10.1073/ pnas.1104558108.

31. Lin HC, Mao SC, Gean PW. Block of gamma-aminobutyric acid-A receptor insertion in the amygdala impairs extinction of conditioned fear. Biol Psychiatry. 2009;66(7):665-73. doi:10.1016/j.biopsych.2009.04.003.

32. Washburn MS, Moises HC. Electrophysiological and morphological properties of rat basolateral amygdaloid neurons in vitro. J Neurosci. 1992:12(10):4066-79.

33. Hsiao YH, Kuo JR, Chen SH, Gean PW. Amelioration of social isolation-triggered onset of early Alzheimer's disease-related cognitive deficit by $\mathrm{N}$-acetylcysteine in a transgenic mouse model. Neurobiol Dis. 2012;45(3):1111-20. doi:10.1016/j.nbd.2011.12.031.

34. Ahmad M, Polepalli JS, Goswami D, Yang X, Kaeser-Woo YJ, Sudhof TC, et al. Postsynaptic complexin controls AMPA receptor exocytosis during LTP. Neuron. 2012;73(2):260-7. doi:10.1016/j.neuron.2011.11.020.

35. Luscher C, Malenka RC. NMDA receptor-dependent long-term potentiation and long-term depression (LTP/LTD). Cold Spring Harb Perspect Biol. 2012;4(6). doi:10.1101/cshperspect.a005710.

36. Makino H, Malinow R. AMPA receptor incorporation into synapses during LTP: the role of lateral movement and exocytosis. Neuron. 2009;64(3):381-90. doi:10.1016/j.neuron.2009.08.035.

37. Matsuda S, Kakegawa W, Budisantoso T, Nomura T, Kohda K, Yuzaki M. Stargazin regulates AMPA receptor trafficking through adaptor protein 
complexes during long-term depression. Nat Commun. 2013;4:2759. doi:10.1038/ncomms3759.

38. Fole A, Miguens M, Higuera-Matas A, Alguacil LF, Ambrosio E, Del Olmo N. Cocaine facilitates protein synthesis-dependent LTP: the role of metabotropic glutamate receptors. Eur Neuropsychopharmacol. 2014;24(4):621-9. doi:10.1016/j.euroneuro.2013.10.013.

39. Deng Y, Theken KN, Lee CR. Cytochrome P450 epoxygenases, soluble epoxide hydrolase, and the regulation of cardiovascular inflammation. J Mol Cell Cardiol. 2010;48(2):331-41. doi:10.1016/j.yjmcc.2009.10.022.

40. Cowley TR, Fahey B, O'Mara SM. COX-2, but not COX-1, activity is necessary for the induction of perforant path long-term potentiation and spatial learning in vivo. Eur J Neurosci. 2008;27(11):2999-3008. doi:10.1111/j.14609568.2008.06251.x.

41. Zucker RS, Regehr WG. Short-term synaptic plasticity. Annu Rev Physiol. 2002;64:355-405. doi:10.1146/annurev.physiol.64.092501.114547.

42. Liu Y, Zhang Y, Schmelzer K, Lee TS, Fang X, Zhu Y, et al. The antiinflammatory effect of laminar flow: the role of PPARgamma, epoxyeicosatrienoic acids, and soluble epoxide hydrolase. Proc Natl Acad Sci U S A. 2005:102(46):16747-52. doi:10.1073/pnas.0508081102.

43. Norwood S, Liao J, Hammock BD, Yang GY. Epoxyeicosatrienoic acids and soluble epoxide hydrolase: potential therapeutic targets for inflammation and its induced carcinogenesis. Am J Transl Res. 2010;2(4):447-57.

44. Malenka RC, Bear MF. LTP and LTD: an embarrassment of riches. Neuron. 2004;44(1):5-21. doi:10.1016/..neuron.2004.09.012.

45. Soderling TR, Derkach VA. Postsynaptic protein phosphorylation and LTP. Trends Neurosci. 2000;23(2):75-80.

46. Strack S, McNeill RB, Colbran RJ. Mechanism and regulation of calcium/ calmodulin-dependent protein kinase II targeting to the NR2B subunit of the N-methyl-D-aspartate receptor. J Biol Chem. 2000;275(31):23798-806. doi:10.1074/jbc.M001471200.

47. Chen G, Xu R, Wang Y, Wang P, Zhao G, Xu X, et al. Genetic disruption of soluble epoxide hydrolase is protective against streptozotocin-induced diabetic nephropathy. Am J Physiol Endocrinol Metab. 2012;303(5):E563-75. doi:10.1152/ajpendo.00591.2011

48. Del Olmo N, Higuera-Matas A, Miguens M, Garcia-Lecumberri C, Borcel E, Solis JM, et al. Hippocampal synaptic plasticity and water maze learning in cocaine self-administered rats. Ann N Y Acad Sci. 2006;1074:427-37. doi:10.1196/annals.1369.043.

49. Selcher JC, Nekrasova T, Paylor R, Landreth GE, Sweatt JD. Mice lacking the ERK1 isoform of MAP kinase are unimpaired in emotional learning. Learn Mem. 2001;8(1):11-9. doi:10.1101//m.37001.

50. Selcher JC, Weeber EJ, Christian J, Nekrasova T, Landreth GE, Sweatt JD. A role for ERK MAP kinase in physiologic temporal integration in hippocampal area CA1. Learn Mem. 2003;10(1):26-39. doi:10.1101/Im.51103.

51. Williams JH, Bliss TV. An in vitro study of the effect of lipoxygenase and cyclo-oxygenase inhibitors of arachidonic acid on the induction and maintenance of long-term potentiation in the hippocampus. Neurosci Lett. 1989;107(1-3):301-6.

52. Winder DG, Martin KC, Muzzio IA, Rohrer D, Chruscinski A, Kobilka B, et al. ERK plays a regulatory role in induction of LTP by theta frequency stimulation and its modulation by beta-adrenergic receptors. Neuron. 1999;24(3):715-26.

53. Akirav I, Maroun M. The role of the medial prefrontal cortex-amygdala circuit in stress effects on the extinction of fear. Neural Plast. 2007;2007:30873. doi:10.1155/2007/30873.

54. Alkayed NJ, Birks EK, Hudetz AG, Roman RJ, Henderson L, Harder DR. Inhibition of brain P-450 arachidonic acid epoxygenase decreases baseline cerebral blood flow. Am J Physiol. 1996;271(4 Pt 2):H1541-6.

55. Das SR, Magnusson KR. Changes in expression of splice cassettes of NMDA receptor GluN1 subunits within the frontal lobe and memory in mice during aging. Behav Brain Res. 2011;222(1):122-33. doi:10.1016/ j.bbr.2011.03.045

56. Devito LM, Eichenbaum H. Memory for the order of events in specific sequences: contributions of the hippocampus and medial prefrontal cortex. J Neurosci. 2011;31(9):3169-75. doi:10.1523/JNEUROSCI.4202-10.2011.

57. Radley JJ, Williams B, Sawchenko PE. Noradrenergic innervation of the dorsal medial prefrontal cortex modulates hypothalamo-pituitary-adrenal responses to acute emotional stress. J Neurosci. 2008;28(22):5806-16 doi:10.1523/JNEUROSCI.0552-08.2008.

58. Dorrance AM, Rupp N, Pollock DM, Newman JW, Hammock BD, Imig JD. An epoxide hydrolase inhibitor, 12-(3-adamantan-1-yl-ureido)dodecanoic acid
(AUDA), reduces ischemic cerebral infarct size in stroke-prone spontaneously hypertensive rats. J Cardiovasc Pharmacol. 2005;46(6):842-8.

59. Fujimoto S, Katsuki H, Kume T, Kaneko S, Akaike A. Mechanisms of oxygen glucose deprivation-induced glutamate release from cerebrocortical slice cultures. Neurosci Res. 2004;50(2):179-87. doi:10.1016/j.neures.2004.06.013.

60. Lin $\mathrm{CH}$, Chen PS, Gean PW. Glutamate preconditioning prevents neuronal death induced by combined oxygen-glucose deprivation in cultured cortical neurons. Eur J Pharmacol. 2008:589(1-3):85-93. doi:10.1016/ j.ejphar.2008.05.047.

\section{Submit your next manuscript to BioMed Central and take full advantage of:}

- Convenient online submission

- Thorough peer review

- No space constraints or color figure charges

- Immediate publication on acceptance

- Inclusion in PubMed, CAS, Scopus and Google Scholar

- Research which is freely available for redistribution 